\title{
O ensino de história em tempos de ensino remoto
}

\author{
Thiago da Silva Nobre \\ Universidade Estadual do Ceará ${ }^{1}$
}

\begin{abstract}
Resumo: Este artigo pretende compreender as relações entre educação e tecnologia, assim como entender também as particularidades para tentar esboçar tendências mais gerais. Utilizamos os planejamentos de aula e as avaliações de três professores da cidade de Fortaleza (Ceará), do $9^{\mathrm{a}}$ ano do Ensino Fundamental ao $3^{\circ}$ do Ensino Médio durante maio a dezembro de 2020. O que percebemos, nessas relações entre educação e tecnologia, foi que "da noite para o dia" milhões de professores e estudantes tiveram que se adaptar rapidamente à nova realidade de aulas remotas e uso massivo de Tecnologias Digitais da Comunicação e da Informação (TDIC's), ambientes virtuais de aprendizagem (AVA's), etc. Muitas vezes tendo que dispor de seus próprios meios para utilizarem essas tecnologias. O que percebemos, também, foi que as mudanças na relação entre educação e tecnologia se deram principalmente nas formas e maneiras de ensinar mediada por tecnologias, em detrimento de modificações nos conteúdos ensinados.
\end{abstract}

Palavras-chave: Ensino de História; Tecnologias Educacionais; Ensino Remoto Emergencial.

\section{History teaching in times of remote learning}

\begin{abstract}
This article intends to understand the relationship between education and technology, as well as to understand the particularities in order to try to outline more general trends. We used the lesson plans and assessments of three teachers from the city of Fortaleza (Ceara), from the 9 th grade of Elementary School to the 3rd of High School from May to December 2020. What we realized, in these relationships between education and technology, was that "overnight" millions of teachers and students had to quickly adapt to the new reality of remote classes and massive use of Communication and Information Technologies (ICT's), virtual learning environments ( $A V A$ 's), etc. Often having to have their own means to use these technologies. What we also noticed was that the changes in the relationship between education and technology took place mainly in the forms and ways of teaching mediated by technologies, to the detriment of changes in the content taught.
\end{abstract}

Keywords: History teaching; Educational Technologies; Emergency Remote Learning.

\footnotetext{
${ }^{1}$ Mestre em História pela Universidade Estadual do Ceará (UECE). ORCiD: https://orcid.org/0000-00030212-0148. E-mail: thiagonobree@gmail.com.
}

Cadernos GPOSSHE On-line, Fortaleza, v. 5, n. 1, 2021

https://revistas.uece.br/index.php/CadernosdoGPOSSHE

DOI: $10.33241 /$ cadernosdogposshe.v5i1

ISSN: $2595-7880$ 


\section{INTRODUÇÃO}

Este artigo pretende compreender as relações entre educação e tecnologia a partir das possibilidades e contradições impostas pelo contexto de pandemia mundial. Relações essas, é importante salientar, que já vinham acontecendo de maneira gradual e progressiva, mas que a pandemia impôs objetivamente como saída possível para a continuidade das aulas e dos sistemas de ensino ao redor do mundo.

Escolhemos o Ensino de História para tentar apreender o movimento das práticas de ensino mediadas por Tecnologias Digitais da Comunicação e da Informação (TDIC's), em uma realidade que está cada vez mais comum a alternância de aulas presenciais e remotas, assim como atividades pedagógicas síncronas e assíncronas. Utilizamos como material para a nossa pesquisa os planejamentos de aulas ${ }^{2}$ e as avaliações de três professores de História da cidade de Fortaleza (Ceará), do $9^{a}$ ano do Ensino Fundamental ao $3^{\circ}$ do Ensino Médio de maio a dezembro de 2020.

Em um mundo que a Internet, as Tecnologias Digitais da Comunicação e da Informação (TDIC's), as tecnologias educacionais, Educação a Distância (EaD) etc., estão em um processo de expansão frenética, a pandemia da doença COVID-19³ causado pelo vírus SARS-CoV-2 $2^{4}$, impôs novos desafios e possibilidades para a educação e para a vida em todo o planeta. Todos os países ao redor do globo tiveram que encontrar saídas concretas para os seus sistemas de ensino.

Tudo foi muito rápido. Em dezembro de 2019, a Organização Mundial de Saúde (OMS) foi alertada pela China sobre a ocorrência de uma estranha e misteriosa doença respiratória na cidade de Wuhan. Em 07 de janeiro de 2020, as autoridades chinesas confirmaram que se tratava de um novo tipo de coronavírus. Em seguida, a 11 de março de 2020, a OMS declarou pandemia da COVID-19. A definição de pandemia não depende de

\footnotetext{
2 Tivemos acesso tanto aos planos de aula como aos planejamentos semestrais e anuais.

${ }^{3}$ Corona Virus Disease (Doença do Coronavírus). Doença causada pelo Sars-Cov-2.

4 SARS-CoV-2 significa, em inglês, severe acute respiratory syndrome coronavirus 2 (síndrome respiratória aguda grave de coronavírus 2). Recebeu essa nomenclatura por possuir grande semelhança com o vírus SARSCoV, agente causador da epidemia de SARS, em 2002.
} 
um número específico de casos, mas sim da contaminação de um grande número de pessoas espalhadas pelo mundo.

No Brasil foram confirmados 34 casos no dia 10 de março, sem mortes. Já na Itália, foram 9.172, com 463 mortes, e na China foram 80.924 infecções, com 3.140 óbitos. O que levou as autoridades brasileiras, e em certo sentido todos nós, a subestimarem o vírus e a atrasarem medidas mais enérgicas como, por exemplo, a quarentena e o isolamento social rígido (lockdown).

A cidade de Fortaleza (CE) foi a $3^{a}$ capital a implantar o isolamento social rígido (lockdown), já em 8 de maio de 2020, depois de Belém (PA) e São Luís (MA). Após 23 dias de lockdown em Fortaleza e de 72 dias de quarentena no Ceará, foi lançado o "Plano de Retomada Responsável das Atividades Econômicas e Comportamentais do Estado do Ceará", iniciando sua fase de transição em $1^{\circ}$ de junho de 2020. O plano contém 4 fases no qual estão explicitados os protocolos específicos para cada setor econômico, a porcentagem de pessoal e os critérios sanitários para funcionamento dos estabelecimentos.

Até então, dezembro de 2020, Fortaleza e macrorregião se encontram na Fase 4, o que significou o retorno das instituições educacionais do ramo privado, respeitando as porcentagens de limitação da capacidade ${ }^{5}$ e as medidas sanitárias ${ }^{6}$. A perspectiva de retorno das aulas presenciais do sistema público de educação está para fevereiro de 2021. Lembrando que no Ceará as aulas presenciais foram suspensas em março de 2020, sendo autorizadas a retomar em $1^{\circ}$ de setembro para turmas do ensino infantil das escolas particulares.

\section{EDUCAÇÃO E TECNOLOGIA}

De uma forma geral, a saída encontrada para contornar a suspensão das aulas presenciais e para continuar as atividades pedagógicas foi a do Ensino Remoto Emergencial

\footnotetext{
5 Segundo o Decreto N³3.846, de 12 de dezembro de 2020, publicado no Diário Oficial do Estado do Ceará, os limites de capacidade nas intuições de ensino está estabelecido assim: Último ano do ensino profissionalizante $(35 \%), 3^{\circ}$ ao $8^{\circ}$ anos do Ensino fundamental (35\%), Cursos preparatórios para acesso ao ensino superior (35\%), Educação Infantil (75\%), Educação de Jovens e Adultos - EJA (35\%), $9^{\circ}$ ano Ensino Fundamental (35\%), $3^{\mathrm{a}}$ série do Ensino Médio (35\%), $1^{\circ}$ ano e $2^{\circ}$ ano Ensino Fundamental (35\%) etc.

6 As medidas sanitárias para o ramo educacional estão descritas no documento Protocolo Setorial 18 Atividades Educacionais, do Governo Estadual do Ceará.
}

Cadernos GPOSSHE On-line, Fortaleza, v. 5, n. 1, 2021

https://revistas.uece.br/index.php/CadernosdoGPOSSHE

DOI: $10.33241 /$ cadernosdogposshe.v5i1

ISSN: $2595-7880$ 
(ERE). Muitos autores levantam uma muralha impenetrável entre Ensino Remoto e a Educação a Distância, entendendo a $\mathrm{EaD}$, de forma cristalizada e estanque, como uma modalidade de ensino que pressupõe necessariamente design educacional, ambiente virtual de aprendizagem (AVA), metodologias ativas, objetos de aprendizagem (OA), atividades síncronas e assíncronas, equipe interdisciplinar, tutores, professores-conteudistas, dentre outros. Já outros autores consideram o Ensino Remoto como “[...] uma sub especificidade da Educação a Distância (EAD)" (PIMENTEL; SILVA JÚNIOR; CARDOSO, 2020, p. 95).

Nós vamos um pouco mais longe, consideramos o Ensino Remoto como uma forma de Educação a Distância. É evidente que ela tem suas particularidades e é mais limitada do que a forma atual consolidada de $\mathrm{EaD}$, que possui desenho educacional, AVA, objetos de aprendizagem, metodologias ativas, etc. Mesmo com suas particularidades e limitações continua sendo EaD. Pois é possível fazer um curso inteiro ou uma formação política com aulas remotas (síncrono) ou com aulas gravadas (assíncrono). É uma contradição candente desconsiderar o Ensino Remoto como uma forma de EaD e, pelo contrário, considerar tranquilamente como EaD o ensino por correspondência, a radioaula, a videoaula, a teleaula. Não faz sentido algum manter esses dois posicionamentos sem cair um enorme contrassenso.

Muitos defendem essa posição com o objetivo de defender a $\mathrm{EaD}$ como uma modalidade de ensino legítima, o que não deixa de ser louvável mas não menos contraditório. No entanto, não podemos desenvolver ou aprofundar essa polêmica aqui, só queremos deixar em relevo a nossa concepção de que o Ensino Remoto é uma forma possível de EaD, por certo mais limitada e, a depender do contexto concreto, não sendo a melhor opção para se utilizar isoladamente e sem um sólido planejamento pedagógico.

É por isso que Ivônio B. Nunes (2019) nos alerta que o processo de integração entre educação presencial e educação a distância será cada vez mais comum. No entanto, esse processo está se dando há pelo menos 20 anos, apesar de já ser praticado em vários lugares do mundo, inclusive no Brasil. Mas ainda há um longo processo de desenvolvimento, implantação e adaptação dessa "[...] nova maneira de educação, na qual a presencialidade se dará por um amálgama de formas e usos de tecnologias [...]" (NUNES, 2009, p. 02). 
Mas se pensarmos a educação e a tecnologia de uma forma abrangente, ambas sempre estiveram em inextricável relação. Talvez o trabalho ${ }^{7}$ e a linguagem ${ }^{8}$ tenham sido umas das formas iniciais de produção e transmissão de conhecimento, e logo em seguida a língua articulada e a cultura oral. Nesse sentido, a dimensão educativa é parte inerente do ser social e das sociedades humanas no tempo e no espaço, pois "ninguém escapa da educação" (BRANDÃO, 2007). Ou seja, ninguém escapa aos processos educativos e de interiorização da cultura intrínsecos às sociedades humanas.

A tecnologia deve ser entendida, em última instância, como saber-fazer, ou seja, como um conhecimento que se objetiva objetivada pelo trabalho humano. Pressupõe necessariamente a existência de um sujeito cognoscente e de um objeto cognoscível, ou seja, de uma realidade concreta, independente das vontades, representações e idealizações humanas, possuindo uma legalidade própria na qual deve ser minimamente compreendida e dominada para garantir a produção e reprodução da vida. Ou seja, "[...] a técnica não é uma força sobre si mesma, mas uma consequência do movimento das forças produtivas. Ela depende da estrutura social" (LUKÁCS, 2020, p. 31).

Vani M. Kenski (2011) enfrenta a questão entre educação e tecnologia colocando a ênfase da sua análise na engenhosidade e raciocínio humanos para o desenvolvimento constante de inovações tecnológicas, o que ao nosso ver ainda é insuficiente pois falta a mediação da categoria trabalho em uma perspectiva ontológica, como veremos a seguir. Mas ela corretamente ressalta a indissociabilidade entre educação e tecnologia, bem como não esquece de salientar os vínculos entre relações de poder e tecnologia.

Pierre Lévy (1999) também reflete sobre o papel da tecnologia nas sociedades humanas, suas implicações e potencialidades, e que apesar de nossas discordâncias teóricometodológicas, reconhecemos que em vários momentos ele têm intuições interessantes, mesmo que limitadas. Para o autor francês a tecnologia é produto de uma sociedade e uma cultura, sendo impossível separar a humanidade do ambiente material, dos dos signos e das ideias por meio dos quais homens e mulheres dão sentido à vida.

\footnotetext{
${ }^{7}$ Compreendemos o trabalho como categoria fundante do ser social.

8 Entendemos a linguagem no sentido mais geral, como as múltiplas formas de se comunicar, que não necessariamente sejam mediadas pela língua articulada.
} 
Frederico Costa (2001) nos lembra que os homens e as mulheres transformam a natureza para satisfazer suas necessidades, conhecendo progressivamente a realidade e produzindo conhecimento sobre ela. Tal conhecimento é produto da atividade humana, ambos socialmente determinados e historicamente construídos.

A imediata e primeira atitude dos homens e das mulheres em face da realidade não é de um abstrato sujeito cognoscente, de uma consciência que reflete o mundo fora do mundo, mas sim a de um indivíduo histórico que tem uma práxis objetiva ao se relacionar com a natureza e outros indivíduos, "tendo em vista a consecução dos próprios fins e interesses, dentro de um determinado conjunto de relações sociais (KOSIK, 1989, p. 9, 10).

O homem é um ser que responde, ou seja, que dá respostas concretas a uma realidade que existe independente de seus anseios, vontades, representações e idealizações, o que não significa menosprezar e ignorar essas dimensões do ser social, mas que elas devem ser integradas na totalidade da vida (LUKÁCS, 2020).

Foi "[...] o trabalho que tornou homem o homem" (LUKÁCS, 2020, p. 38), ou dito com outras palavras, foi o trabalho a categoria fundante do ser social permitindo o salto ontológico entre organismo estritamente biológico e sociedade. O trabalho pressupõe relações teleológicas (finalidade) e causais (causa/efeito), ou seja, a canoa, a vara de pescar ou a machadinha existem antes na cabeça do ser social. Para que esses utensílios sejam objetivados é necessário escolher adequadamente o material e as formas de trabalhar esse material, o que não garante que a antecipação do objeto na cabeça (prévia-ideação) seja exatamente o que foi objetivado. No entanto, quanto maior o domínio da natureza menor é a distância entre (prévia-ideação) e objetivação.

\section{EDUCAÇÃO A DISTÂNCIA}

Para os leitores que não estão afeitos ao debate sobre Educação a Distância, faremos um voo panorâmico sobre a sua evolução histórica no mundo. Geralmente a literatura aponta o século XVIII como o surgimento da Educação a Distância com a experiência dos cursos por correspondência. Exemplo disso foram os cursos oferecidos por Caleb Philips (1728 EUA), Isaac Pitman (1840 - Grã-Bretanha), Skerry's College (1880 - Grã-Bretanha), Foulkes 
Lynch Correspondence Tuition Service (1884 - Grã-Bretanha), Thomas J. Foster (1891 EUA) etc.

E entre o fim do século XIX e o início do século XX várias instituições universitárias começaram a oferecer cursos por correspondência como, por exemplo, as universidades de Oxford e Cambridge (Grã-Bretanha), as universidades de Chicago e Wisconsin (EUA), a Universidade de Queensland (AUS) etc. Nesse sentido também é interessante citar a experiência de radioaulas desenvolvida pela British Broadcasting Corporation (BBC).

Ainda durante o século XX várias experiências de cursos por correspondência foram surgindo, inclusive para treino militar como por exemplo os cursos de Código Morse. Porém, Nunes (2009) sustenta que o grande impulso se deu na década de 1960, com a institucionalização de experiências de Educação a Distância no ensino secundário e superior. E também nos anos subsequentes a EaD teve outros impulsos com o desenvolvimento da Internet, da Web, das Tecnologias Digitais da Informação e Comunicação (TIC's), dos Ambientes Virtuais de Aprendizagem (AVA's).

No Brasil a História da Educação é descontínua e acidentada, repleta de avanços e retrocessos. Não é de surpreender que a História da Educação a Distância, no Brasil, também seja marcada por instabilidade, descontinuidade e fragilidade das políticas públicas. E, também, não é à toa que a Universidade Aberta do Brasil (UAB) só foi criada em 2006?", enquanto outros países perceberam muito antes a importância da $\mathrm{EaD}$ e organizaram as suas Universidades Abertas e os seus sistemas abertos de ensino entre o final do século XIX e durante todo o século $\mathrm{XX}^{10}$.

Não caberia aqui apresentar o desenvolvimento histórico da EaD em solo nacional, devido ao espaço que dispomos, mas pelo menos desde o século XIX é possível encontrar anúncios na imprensa de cursos de datilografia por correspondência (ALVES, 2009).

\footnotetext{
${ }^{9}$ Decreto $n^{\circ} 5.800$, de 8 de junho de 2006.

10 Podemos citar alguns exemplos como a Faculdade de Ensino Dirigido (1979 - Cuba), Universidade Athabasca (1973 - Canadá), Universidade da Pensilvânia (1892 - EUA), Universidade de Stanford (1969 EUA), Universidade de Utah (1916 - EUA), Universidade de Ohio (1924 - EUA), Universidade de Queensland (1910 - Austrália), Programa de pós-graduação em Educação (1985 - Bangladesh), Departamento de Educação por Correspondência da Universidade do Povo (1951 - China), Universidade de Hong Kong (1956 - China), Universidade de Délhi (1962 - Índia), Universidade Chuo (1948 - Japão), Universidade Aberta da Indonésia (1984 - Indonésia), Universidade Aberta de Portugal (1984 - Portugal), Universidade Nacional de Educação a Distância (1972 - Espanha), Universidade Nacional Aberta da Venezuela (1976 - Venezuela), Universidade Estatal a Distância da Costa Rica (1978 - Costa Rica), Universidade Aberta (1969 - Reino Unido) etc.
}

Cadernos GPOSSHE On-line, Fortaleza, v. 5, n. 1, 2021 
Variadas foram as experiências da EaD no Brasil, tanto na forma como no conteúdo: [1] Ensino por Correspondência, [2] Radioaulas, [3] Telecursos, [4] Ambientes Virtuais de Aprendizagem (AVA's).

E um dos grandes marcos de reconhecimento institucional da Educação a Distância $(\mathrm{EaD})$ foi a Lei de Diretrizes e Bases (LDB), sobretudo no seu art. 80 que estabelece que "O Poder Público incentivará o desenvolvimento e a veiculação de programas de ensino a distância, em todos os níveis e modalidades de ensino, e de educação continuada" (BRASIL, 1996).

Quase 10 anos depois foi criado o Sistema Universidade Aberta do Brasil (UAB), que segundo o seu art. $1^{\circ}$ será “[...]voltado para o desenvolvimento da modalidade de educação a distância, com a finalidade de expandir e interiorizar a oferta de cursos e programas de educação superior no País. E dos quais os principais objetivos mencionamos a ampliação prioritária de licenciaturas e de formação inicial e continuada para professores da educação básica, o oferecimento de cursos superiores em diferentes áreas do conhecimento, ampliação do acesso à educação superior pública, a redução das desigualdades de oferta de ensino superior entre as diferentes regiões do País e o fomento ao desenvolvimento institucional da modalidade de educação a distância (BRASIL, 2006).

Dermeval Saviani e Ana Carolina Galvão (2021) nos mostram dados importantes sobre a adesão ao ensino remoto no Brasil, a partir de pesquisa realizada pelo DataSenado em julho de 2020. No qual de um montante de quase 56 milhões de estudantes brasileiros matriculados na educação básica e superior, 19,5 milhões (35\%) tiveram as aulas presenciais suspensas e 32,4 milhões (58\%) tiveram que se adaptar às aulas remotas. E até então 40 unidades de Institutos Federais haviam aderido ao ensino remoto contabilizando mais de 925 mil alunos, bem como todas as Universidades Federais contabilizando mais de 1 milhão e 100 mil estudantes ${ }^{11}$.

O autor, em sua correta defesa do ensino presencial e de uma educação pública, democrática, de qualidade e para todos, logo se põe contra o ensino remoto e a Educação a Distância $(\mathrm{EaD})$ ressaltando apenas as determinações negativas como, por exemplo, os interesses privatistas, a concepção da educação como mercadoria, a exclusão digital e

\footnotetext{
${ }^{11}$ No Estado do Ceará tanto universidades estaduais como as particulares fizeram a opção pelo ensino remoto.
} 
tecnológica, a ausência de democracia na adoção dessas modalidades, a precarização e intensificação do trabalho etc., afirmando que "A docência 'uberizada' terá na experiencia do 'ensino' remoto uma alavanca a serviço dos interesses mercadológicos pós-pandemia" (GALVÃO, SAVIANI, p. 39). O que não deixa de ser verdadeiro e passível de duras críticas, mas que, ao nosso juízo, é abordar a questão de maneira unilateral, não percebendo a riqueza de mediações contraditórias existentes nessas formas de ensino. Não é que como se educação presencial estivesse fora dos interesses do capital e também não estivesse sob a lógica de precarização. É necessário compreender bem as mediações.

Galvão e Saviani (2021) também defendem que "pela sua própria natureza, educação não pode não ser presencial", pois pressupondo uma relação interpessoal ela só pode acontecer com a existência simultânea dos dois agentes da atividade educativa (professor e alunos) em um contexto presencial. O que soa estranho e atabalhoado, para dizer o mínimo, conceber um "ser", uma "natureza" ou uma "essência" a-históricos da educação, ou seja, entender o processo de ensino-aprendizagem de uma maneira petrificada, cristalizada e imutável no tempo e no espaço, sem nenhuma historicidade e mediações concretas, negando as várias formas de aprender e de ensinar que existiram e possam existir nas sociedades humanas, além de excluir totalmente a possibilidade de que modalidade presencial e modalidade a distância possam se complementar ao invés de estarem fadadas ao destino inescapável de se anularem e se destruírem.

Os autores conseguem perceber lucidamente as determinações negativas do ensino remoto como, por exemplo, a intensificação e precarização do trabalho, o adoecimento de professores e estudantes (ansiedade, depressão, compulsão etc.), a exclusão digital e tecnológica, bem como dificuldades concretas de toda sorte. Mas não conseguem ou não querem reconhecer que o ensino remoto e a Educação a Distância $(\mathrm{EaD})$ podem ajudar na disseminação de ideias e debates progressistas de esquerda, anticapitalistas e críticos, para um público infinitamente maior do que os auditórios esvaziados de universidades públicas ${ }^{12}$.

\footnotetext{
12 Para não irmos longe nas várias tecnologias em mídias existentes (Podcast, Discord, Twitch.tv etc.), basta olhar os vários canais progressistas de esquerda criados na plataforma de vídeo YouTube, entre 5 e 10 anos até o ano corrente, local dominando pela direita conservadora e reacionária. A ocupação desse espaço se deu recentemente. O que demonstra uma dificuldade, resistência ou negação de uma grande parte da esquerda de utilizar as novas tecnologias e mídias ao seu favor no debate ideológico para a conquista de mentes e corações. Podemos citar como exemplo os canais, mesmo incorrendo em várias faltas e ausências, Humberto Teixeira,
} 
Condenar o ensino remoto e a Educação a Distância $(\mathrm{EaD})$ à danação eterna das formas impuras e pestilentas de educação, sem compreender as possibilidades e as contradições, é apenas atacar o sintoma dos problemas e não a causa efetiva. No qual sabemos muito bem que é a sociabilidade capitalista que produzimos e reproduzimos todos os nossos dias.

A seguir discutiremos sobre as possibilidades e contradições do Ensino de História em tempos de Ensino Remoto Emergencial (ERE), no contexto da maior pandemia enfrentada pela humanidade no último século.

\section{ENSINO DE HISTÓRIA EM TEMPOS DE PANDEMIA DE COVID-19}

Não precisamos reconstruir todo o percurso do Ensino de História no Brasil para constatar que ele também foi caracterizado por descontinuidades, assim como a educação brasileira em geral. Nesse sentido, a colonialidade, o subdesenvolvimento e a posição periférica no capitalismo determinaram de forma indelével as potencialidades, os limites e as contradições das experiências educacionais no Brasil. Basta lembrar-nos a experiência da Ditadura Civil-Militar (1984 - 1985) e o seu legado para a educação nacional.

Para além dos investimentos, políticas públicas, currículo, terrorismo estatal etc., o binômio segurança nacional e desenvolvimento econômico ditaram a reforma institucional da formação dos professores em um processo de desqualificação/requalificação para os interesses do regime militar. Os ataques à formação dos professores foram empreendidos em vários flancos.

Mas avancemos em nosso estudo. Enquanto nós subestimávamos o vírus assistindo notícias aterradoras da China e da Itália, e também pensávamos dentro de nossas bolhas sociais que era só uma "gripezinha" ou que aqui esse "bicho" não chegaria tão cedo, fomos surpreendidos em nossa ignorância e despreparados começamos o combate contra o invisível. "Da noite para o dia" professores experientes e acostumados com a sala de aula, o

Jones Manoel, João Carvalho, Juliane Furno, Sabrina Fernandes, Doutora Drag, Tempero Drag, Silvio Almeida, Chavoso da USP, Laura Sabino, TV Boitempo, Expressão Popular, TV 247, TV dos Trabalhadores (TVT), Brasil de Fato, Rádio Brasil Atual e muitos outros.

Cadernos GPOSSHE On-line, Fortaleza, v. 5, n. 1, 2021

https://revistas.uece.br/index.php/CadernosdoGPOSSHE

DOI: $10.33241 /$ cadernosdogposshe.v5i1

ISSN: $2595-7880$ 
pincel, a lousa e, quando muito, com a projeção de slides, tiveram que repensar as maneiras de ensinar e as sus práticas pedagógicas devido ao novo contexto pandêmico.

Logo abaixo o leitor poderá ver um quadro resumido do material que tivemos acesso à pesquisa ${ }^{13}$ :

\begin{tabular}{|c|c|c|c|c|c|}
\hline Professor(a) & Ensino (Nível) & Série(s) & Escola & Material & Temporalidade \\
\hline A & Fundamental II & $9^{\circ}$ ano & Particular & $\begin{array}{c}\text { Planejamentos e } \\
\text { Avaliações }\end{array}$ & $\begin{array}{c}\text { Maio }- \\
\text { Dezembro } \\
(2020)\end{array}$ \\
\hline B & Médio & $\begin{array}{c}1^{\circ}, 2^{\circ} \text { e } 3^{\circ} \\
\text { anos }\end{array}$ & Pública & $\begin{array}{c}\text { Planejamentos e } \\
\text { Avaliações }\end{array}$ & $\begin{array}{c}\text { Maio - } \\
\text { Dezembro } \\
(2020)\end{array}$ \\
\hline C & Médio & $\begin{array}{c}1^{\circ}, 2^{\circ} \text { e } 3^{\circ} \\
\text { anos }\end{array}$ & Particular & $\begin{array}{c}\text { Planejamentos e } \\
\text { Avaliações }\end{array}$ & $\begin{array}{c}\text { Maio - } \\
\text { Dezembro } \\
(2020)\end{array}$ \\
\hline
\end{tabular}

Quadro 1 - Material Utilizado na Pesquisa

Fonte: NOBRE, 2021.

Para a construção da nossa análise sobre o Ensino de História na sua forma de ensino remoto, dispomos de materiais de três professores de escolas da cidade de Fortaleza (Ceará). Utilizamos, sobremaneira, os planejamentos de aula e as avaliações desses professores para tentar perceber as mudanças tanto no conteúdo quanto na forma de ensinar História em tempos de pandemia de Covid-19. Conversas informais, porém muito informativas, também nos ajudaram a conceber melhor o cotidiano repleto de contradições desses profissionais que com sua astúcia, perseverança e inteligência se reinventam todos os dias.

No quadro abaixo fizemos uma síntese com recursos e avalições utilizados pelos professores estudados:

\footnotetext{
${ }^{13}$ Escolhemos substituir os nomes reais dos professores por letras do alfabeto, pois em tempos de censura e perseguição política cuidado nunca é demais para proteger os companheiros de classe.

Cadernos GPOSSHE On-line, Fortaleza, v. 5, n. 1, 2021

https://revistas.uece.br/index.php/CadernosdoGPOSSHE

DOI: $10.33241 /$ cadernosdogposshe.v5i1

ISSN: $2595-7880$
} 


\begin{tabular}{|c|c|c|c|}
\hline Professor(a) & $\begin{array}{c}\text { Atividades } \\
\text { Pedagógicas }^{14}\end{array}$ & Recursos Pedagógicos e Tecnológicos & Avaliação \\
\hline A & $\begin{array}{c}\text { Síncrona } \\
\text { Assíncrona }\end{array}$ & $\begin{array}{c}\text { Sistema de Ensino Plural, Zoom, Google } \\
\text { Meets }\end{array}$ & $\begin{array}{c}\text { Participação na aula } \\
\text { remota } \\
\text { Google Forms }\end{array}$ \\
\hline $\mathrm{B}$ & $\begin{array}{l}\text { Síncrona } \\
\text { Assíncrona }\end{array}$ & $\begin{array}{l}\text { Atividades com situações problemas- } \\
\text { problemas, Aulas no Google Classroom, } \\
\text { Videoaulas, Tira-dúvidas com professor, } \\
\text { TD’s, Quiz, Apoio com materiais didáticos } \\
\text { (livro, textos complementares, vídeos) }\end{array}$ & $\begin{array}{l}\text { Participação em atividades } \\
\text { remotas, Aulas Virtuais, } \\
\text { Atividades Avaliativas } \\
\text { (Google Classroom) }\end{array}$ \\
\hline $\mathrm{C}$ & $\begin{array}{l}\text { Síncrona } \\
\text { Assíncrona }\end{array}$ & $\begin{array}{c}\text { Computador, Aplicativo Zoom, Slides, } \\
\text { Vídeos, Livro UNO e } \\
\text { Ambiente Virtual de Aprendizagem } \\
\text { (AVA) Google Classroom, Microsoft } \\
\text { Teams }\end{array}$ & $\begin{array}{l}\text { Interesse demonstrado } \\
\text { pelo tema, participação e } \\
\text { comportamento em sala } \\
\text { de aula e empenho na } \\
\text { solução dos exercícios } \\
\text { exigidos } \\
\text { Google Forms }\end{array}$ \\
\hline
\end{tabular}

Quadro 2 - Modelos de Aula, Recursos Pedagógicos/Tecnológicos e Avaliação Fonte: NOBRE, 2021.

Como mencionado anteriormente, utilizamos os planos de aula e as avaliações de três professores de escolas (públicas e privadas) da cidade de Fortaleza (Ceará), entre maio e dezembro de 2020. Demos ênfase a uma abordagem qualitativa na tentativa de apreender o movimento das relações entre educação e tecnologia em tempos de pandemia e, também, no contexto de disseminação da $\mathrm{EaD}$, do ensino remoto, das tecnologias educacionais etc.

O momento da adesão e implantação do ensino remoto nas escolas foi uma celeuma para instituições educacionais, professores, alunos e pais, era como e estivéssemos tateando desesperados em um quarto escuro. Professores tiveram que por conta própria dispor de material e estrutura em suas casas que viabilizassem gravações, muitas vezes tendo que produzir material didático extra e aprender a utilizar tecnologias educacionais complexas e diversas sem formação ou treinamento adequados. Os estudantes, mesmo acostumados e imersos em um mundo tecnológico, sentiram o baque das mudanças radicais no cotidiano e, também, tiveram que se adaptar à nova realidade educacional.

Logo de início percebemos que o conteúdo a ser abordado no decorrer do ano nas aulas remotas não foi modificado em nada. O que não foi surpresa pois o ensino remoto

\footnotetext{
${ }^{14}$ Entendemos como atividades pedagógicos qualquer ação ou prática ocorrida entre professor e aluno com um objetivo específico, por exemplo, aula remota, videoaula, tira-dúvidas pelo ambiente virtual de aprendizagem (AVA) ou pelo aplicativo de mensagens instantâneas etc.
}

Cadernos GPOSSHE On-line, Fortaleza, v. 5, n. 1, 2021

https://revistas.uece.br/index.php/CadernosdoGPOSSHE

DOI: $10.33241 /$ cadernosdogposshe.v5i1

ISSN: $2595-7880$ 
teve de ser implantado em caráter de emergência. É por isso que o nosso debate abordará, sobremaneira, a forma em detrimento do conteúdo.

E foi exatamente o que a análise dos planos de aulas nos confirmou, que os professores tiverem que adaptar suas metodologias de aula para ultrapassar o desafio do distanciamento social. A prática mais utilizada foi o ensino remoto síncrono, utilizando os mais variados programas de videoconferência (Google Meets, Zoom, Microsoft Teams etc.). Ou seja, os professores ministravam suas aulas em salas virtuais de videoconferência.

Como podemos perceber nos quadros acima, o professor A fez o uso de tecnologias diversas como, por exemplo, o Sistema de Ensino Plural e as plataformas de comunicação Zoom e Google Meets, bem como o Google Forms para a aplicação das avaliações.

No caso do Sistema Plural o aluno tem acesso às videoaulas e às questões comentadas, recebendo pontuação para cada atividade realizada e podendo comparar o seu desempenho com outros "usuários-estudantes". O que já era uma tendência que vinha se esboçando e que o isolamento social imposto pela tragédia sanitária acabou por amplificar, que era é a integração cada vez maior entre educação presencia e educação a distância. O Plural é só um exemplo de sistema de ensino dentre vários outros que disponibilizam aos seus contratantes ambientes virtuais de aprendizagem (AVA's), videoaulas, questões comentadas e material de toda sorte, funcionando como uma sala de aula expandida para além dos muros escolares. O que para bem ou para o mal disponibiliza variedade materiais educativos, chegando a ser até excessivo para os estudantes.

Mas então perguntamos quem está na base da produção desses materiais? Os professores, é evidente. E muitas das vezes o material produzido é pago como prestação de serviços por preços aviltantes e prazos curtos, encaixando-se nos que vários autores estão chamando de uberização ${ }^{15}$, ou seja, a hiper precarização do trabalho sem nenhum tipo de salvaguarda ou seguridade social, o trabalhador é remunerado pelo que produz. Se não

\footnotetext{
15 Para a historiadora Virgínia Fontes (2017) a uberização se caracteriza, em linhas gerais, pelo não propriedade direta das ferramentas e meios de produção, assim como pelo controle do agenciamento. Ou seja, viabilizar o encontro entre "meios de produção, força de trabalho e mercado consumidor, sem intermediação de um 'emprego'. A empresa detém [...] a propriedade dos recursos sociais de produção” (FONTES, 2017. p. 56). É o que a autora chama ironicamente de relação pornográfica, qual seja a concentração de propriedade que permite o controle econômico na etapa que lhe apetece, o controle da extração, a expropriação do mais-valor e seu retorno de volta à propriedade.
} 
produz não recebe, simples assim. Essa é a tendência que podemos observar na relação capital-trabalho do capitalismo contemporâneo, a aniquilação dos direitos trabalhistas e a transformação dos trabalhadores em prestadores de serviço sob demanda do capital.

Para o professor B a situação foi diferente por se tratar de escola pública. No início da transição entre o regime presencial e o remoto se utilizou ferramentas inadequadas como o Facebook e o WhatsApp para manter as atividades pedagógicas, mesmo que de forma improvisada. Em seguida foi celebrado uma parceria entre Governo do Ceará e a empresa Google, disponibilizando os aplicativos do G Suite. Então o professor B passou a utilizar o Google Meets para lecionar nas aulas remotas, o Google Classroom para debates e proposição de atividades da sua disciplina.

Um dado importante foi a grande evasão dos alunos nas aulas remotas, ocasionada por motivos diversos. A saída encontrada foi a junção das turmas de uma mesma série e a redução do tempo de aula. E mesmo assim o professor B chegava a ficar sozinho na sala virtual à espera dos alunos que nunca chegariam.

A professora C, também no âmbito da escola particular, fez uso do Zoom, do Microsoft Teams e do Google Classroom.

Para além das aulas remotas foi imposto aos professores a lógica de produzir vários materiais inéditos e complementares de ensino como vídeos de aulas, tira-dúvidas ou resolução de questões, slides etc. E sem ganhar um centavo a mais os professores, mesmo em teletrabalho, tiveram que trabalhar muito mais para atender as demandas das escolas. Neste sentido, os discentes se viram forçados a se engajar tanto em momentos síncronos (aula remota etc.) e assíncronos (confecção de materiais didáticos diversos etc.).

Pelo o que percebemos, a partir da prática dos três professores, a forma de avaliação que se consolidou foi o uso do Google Forms. Basicamente o Google Forms permite o acesso dos alunos à formulários online servindo como avaliação. No entanto, sabemos que ainda em muitas escolas continua a ser usado o aplicativo Whatsapp como instrumento principal para disponibilização de atividades e avaliações, levando os professores a ter que lidar com inúmeros grupos e conversas privadas, inclusive com demandas fora do horário de trabalho. 
Essas avaliações acabam sendo pesquisadas já que não é bloqueado a internet dos estudantes para a navegação em outros sites. Ou então um pode fazer a prova pelo outro, bastando ter os acessos devidos. Enfim, cabe aos professores entenderem essa particularidade do contexto atual e refletirem sobre o tipo de questão que eles estão elaborando. Se é mais interessante decorar datas, fatos e nomes ou instigar a reflexão e o pensamento crítico do aluno por meio da pesquisa?

Outra característica interessante ressaltada pelos três professores foi sobre as diferenças nas possibilidades de uso de recursos didático-tecnológicos no ensino presencial e remoto. Como sabemos cada escola possui a sua realidade específica, enquanto umas mal dispões de lousa, giz, pincel ou carteira, outras dispões de digital, internet, tablet, laboratório de informática, projetores etc., impondo limites reais aos professores do ensino presencial.

Já no caso do ensino remoto, também com seus limites e contradições abordados acima, o professor dispõe de uma variedade de recursos digitais como, por exemplo, o espelhamento da sua tela de computador para projetar vídeos, músicas, bem como a utilização de objetos de aprendizagem ${ }^{16}$ (OA’s), infográficos, lousas digitais etc. O que, reiteramos, não garante uma boa aula e baixa evasão. Somente queremos ressaltar que precisamos compreender bem as singularidades e particularidades se desejamos fomentar uma articulação minimamente positiva entre presencialidade e virtualidade, para além das contradições e determinações negativas que ambas possuem.

\section{CONSIDERAÇÕES FINAIS}

Infelizmente após um ano de pandemia no Brasil, encontramo-nos novamente em uma situação preocupante e calamitosa. Todas as expectativas de retorno das aulas de maneira "híbrida" e do comércio foram desmentidas pela realidade nua e crua do aumento exponencial de infecções, internações e mortes ocasionadas pela Covid-19.

No Ceará os três primeiros casos de Covid foram registrados em 15/03/20 e a primeira pessoa foi vacinada em 18/01/21. Mesmo com o início atrasado e desarticulado da

\footnotetext{
16 O Objeto de aprendizagem é uma unidade de instrução/ensino reutilizável. Em outras palavras um objeto de aprendizagem pode ser definido como qualquer entidade, digital ou não digital, que possa ser utilizada, reutilizada ou referenciada durante o processo de ensino-aprendizagem mediado por tecnologias.
} 
vacinação no país os casos continuam aumentando, pelo simples motivo da campanha de vacinação estar rastejando e também da fraqueza dos estados em impor e garantir o isolamento social rígido, sem falar nas ações contraditórias entre governo federal e ministério da saúde. É impraticável um isolamento social rígido sem a utilização do apoio das forças armadas e da cooperação entre Federação, Estados e Municípios.

Segundo os dados do G1 SP, até o dia 20/03/21 o total de doses aplicadas no Brasil foram de 15.863.113. Sendo 11.722.280 da $1^{\mathrm{a}}$ dose (5,54\%) e 4.140.833 da $2^{\mathrm{a}}$ dose (1,96\%). Ou seja, ainda não conseguimos imunizar nem 10\% da população brasileira. Já no Ceará 470.398 (5,12\%) receberam a $1^{\text {a }}$ dose e $189.374(2,06 \%)$ a $2^{\text {a }}$ dose. Como podemos reparar ainda temos um longo caminhar nesse círculo infernal que nem o próprio Dante poderia conceber em seus pesadelos mais perturbadores, onde pais, mães, filhos, filhas, tios, tias, avôs e avós estão morrendo sufocados no seco, sem direito algum a uma despedida digna.

É impensável o retorno às aulas presenciais sem testagem ampla e vacinação em massa, assim como o próprio retorno do comércio em geral. O que a realidade vem nos mostrando é que não podemos baixar a guarda nem por um milésimo de segundo e que políticas públicas erradas tem influência direta na condução da crise sanitária, desdobrando-se no aumento de infecções e mortes que poderiam muito bem ser evitadas, sem mencionar também a escassez de insumos essenciais para o tratamento dos infectados por falta planejamento logístico.

A Educação a Distância (EaD), o Ensino Remoto e o Ensino Hibrido são realidades que precisam ser compreendidas em suas concretudes, para fazermos a crítica bem fundamentada e podermos melhor utilizá-las para fins que não sejam o da lógica do capital, da exploração e adoecimento de trabalhadores, da extração de mais-valor etc. Para isso precisamos estudar sistematicamente e metodicamente as singularidades, as particularidades e as universalidades da Educação a Distância (EaD), indo além das aparências e do senso comum. Não adianta somente extrair as suas determinações negativas ou se aferrar a uma concepção apriorística de educação fora tempo, do espaço e das relações sociais concretas, utilizando teorias filosóficas abstratas e muitas vezes antiquadas. Reforçamos mais uma vez, para situações concretas análises concretas.

O método materialista deve ser encarado como um guia para o estudo e um fio condutor da análise e não como um conjunto de abstrações pré-fabricadas ou um modelo acabado no qual a realidade será esquartejada para que seja encaixada no molde da teoria (ENGELS, 2012). Na verdade, 
é a teoria que deve se submeter à validade do real, para isso é imprescindível a pesquisa concreta e a apreensão das particularidades do objeto a que se quer conhecer. Precisamos ir à raiz das coisas, capturar o movimento real e contraditório do ser. Pois afinal de contas, a raiz do homem é o próprio homem (MARX, 2013).

\section{Referências}

ABREU, Martha. SOIHET, Raquel (orgs.). Ensino de história: conceitos, temáticas e metodologia. Rio de Janeiro: Casa da Palavra, 2003.

ALVES, João Roberto Moreira. “A história da EAD no Brasil”. In: LITTO, Fredric Michael. FORMIGA, Manuel Marcos Maciel (org.). Educação a Distância: o estado da arte. São Paulo: Pearson Education do Brasil, 2009. Vol. 1.

ANTUNES, Ricardo. Adeus ao trabalho?: ensaio sobre as metamorfoses e centralidade do mundo do trabalho. $11^{\mathrm{a}}$ ed. São Paulo: Cortez, 2006.

Os sentidos do trabalho: ensaio sobre a negação e a afirmação do trabalho. $3^{a}$ ed. São Paulo: Boitempo, 2000.

BITTENCOURT, Circe Maria Fernandes. Ensino de História: fundamentos e métodos. $2^{\mathrm{a}}$ ed. São Paulo: Cortez, 2008.

BRANDÃO, Carlos Rodrigues. O que é Educação. 49ª reimpressão. São Paulo: Brasiliense, 2007.

BRASIL. Decreto $\mathrm{n}^{\mathrm{o}} 5.800$, de 8 de junho de 2006. Disponível em: http://www.planalto.gov.br/ccivil_03/_Ato2004-2006/2006/Decreto/D5800.htm.

Acesso em: 24/01/2021.

BRASIL. Lei $\mathrm{n}^{\circ}$ 9394, de 20 de dezembro de 1996. Disponível em: http://www.planalto.gov.br/ccivil 03/Leis/L9394.htm. Acesso em: 24/01/2021.

CEARÁ. Decreto n ${ }^{\circ}$ 33.846. Diário Oficial do Estado do Ceará, 12 de dezembro de 2020. Disponível

em:

http://imagens.seplag.ce.gov.br/PDF/20201212/do20201212p01.pdf\#page=19. Acesso em: $20 / 12 / 2020$.

COSTA, Frederico. "O marxismo enquanto referencial teórico para conhecimento do ser social”. In: FURTADO, Elizabeth Bezerra. JIMENEZ, Susana Vasconcelos. Trabalho e 
educação: uma intervenção crítica no campo da formação docente. Fortaleza: Ed. Demócrito Rocha, 2001.

ENGELS, Friedrich. MARX, Karl. Cultura, arte literatura: textos escolhidos. $2^{\mathrm{a}}$ ed. São Paulo: Expressão Popular, 2012.

Entenda o Plano de Retomada Responsável das Atividades Econômicas e Comportamentais.

SEPLAG, 03 de junho de 2020. Disponível em:
https://www.seplag.ce.gov.br/2020/06/03/entenda-o-plano-de-retomada-responsaveldas-atividades-economicas-e-comportamentais/. Acesso em: 14/12/2020.

Fase 1 do plano de reabertura do Ceará terá restrições em algumas regiões, afirma secretário da Saúde. G1, 08 de maio de 2020. Disponível em: https://g1.globo.com/ce/ceara/noticia/2020/06/05/fase-1-do-plano-de-reabertura-doceara-tera-restricoes-em-algumas-regioes-afirma-secretario-da-saude.ghtml. Acesso em: $14 / 12 / 2020$.

FONSECA, Thais Lívia de Lima e. História \& ensino de História. $3^{\text {a }}$ ed. Belo Horizonte: Autêntica Editora, 2011.

FONSECA, Selva Guimarães. Caminhos da História ensinada. São Paulo: Papirus, 1993.

Didática e prática de ensino de história: experiências, reflexões e aprendizados. $12^{\mathrm{a}}$ ed. São Paulo: Papirus, 2011.

FONTES, Virgínia. Capitalismo em tempos de uberização: do emprego ao trabalho. Marx e o Marxismo - Revista do NIEP-Marx, v. 5, n. 8, 2017.

GALVÃO, Ana Carolina. SAVIANI, Dermeval. Educação na Pandemia: a falácia do "ensino" remoto. In: Universidade e Sociedade, ano XXXI, no 67, Brasília: Sindicato Nacional dos Docentes das Instituições de Ensino Superior, 2021.

GHIRALDELLI JR, Paulo. O que é Pedagogia. $3^{a}$ ed. São Paulo: Brasiliense, 1993. HOBSBAWM, Eric. O novo século: entrevista a Antonio Polito. São Paulo: Companhia das Letras, 2000.

Globalização, democracia e terrorismo. São Paulo: Companhia das Letras, 2007.

KOSIK, Karel. Dialética do concreto. $5^{\text {a }}$ Ed. Rio de Janeiro: Paz e Terra, 1989.

KARNAL, Leandro (org.). História na sala de aula: conceitos, práticas e propostas. $5^{\mathrm{a}}$ ed. São Paulo: Contexto, 2007.

KENSKI, Vani Moreira. Educação e tecnologias: O novo ritmo da informação. $8^{\circ}$ ed. Campinas: Papirus, 2011. 
LÉVY, Pierre. Cibercultura. São Paulo: Ed. 34, 1999.

Lockdown contra coronavírus começa em Fortaleza, $3^{\text {a }}$ capital do país a adotar a medida. G1 CE, 05 de junho de 2020. Disponível em: https:/g1.globo.com/ce/ceara/noticia/2020/05/08/lockdown-em-fortaleza-comecanesta-sexta-feira-policia-pode-levar-para-delegacia-quem-descumprir-medidas.ghtml. Acesso em: 14/12/2020.

LUKÁCS, György. Essenciais são os livros não escritos: últimas entrevistas (1966-1971). São Paulo: Boitempo, 2020.

Mapa da vacinação contra a covid-19 no Brasil. G1 SP, 20 de março de 2021. Disponível em: https://especiais.g1.globo.com/bemestar/vacina/2021/mapa-brasil-vacinacovid/? ga=2.240307659.930151498.1616333826-230209049.1615171292. Acesso em: $21 / 03 / 21$.

MARX, Karl. Crítica da filosofia do direito de Hegel. $3^{\text {a }}$ ed. São Paulo: Boitempo, 2013.

MASETTO, Marcos T. "Mediação pedagógica e o uso de tecnologias”. In: MORAN, José Manuel. Novas tecnologias e mediação pedagógica. 19ª edição. Campinas: Papirus, 2011.

MÉSZÁROS, István. A educação para além do capital. $2^{a}$ ed. São Paulo: Boitempo, 2008.

NIKITIUK, Sonia M. Leite (org.). Repensando o Ensino de História. São Paulo: Cortez, 2001.

NUNES, Ivônio Barros. "A história da EAD no mundo". In: LITTO, Fredric Michael. FORMIGA, Manuel Marcos Maciel. Educação a Distância: o estado da arte (orgs.). São Paulo: Pearson Education do Brasil, 2009. Vol. 1.

OMS decreta pandemia do novo coronavírus. Veja, 11 de março de 2020. Disponível em:https://saude.abril.com.br/medicina/oms-decreta-pandemia-do-novo-coronavirussaiba-o-que-isso. Acesso em: 05 de dezembro de 2020.

PAULO NETTO, José. Crise do socialismo e ofensiva neoliberal. São Paulo: Cortez, 1993.

Introdução ao estudo do método de Marx. São Paulo: Expressão Popular, 2011.

PINSKY, JAIME (org.). O Ensino de História e a Criação do Fato. 9a ed. São Paulo: Contexto, 2001. 
Protocolo Setorial 18 - Atividades Educacionais. Disponível em: https://www.ceara.gov.br/wp-content/uploads/2020/09/Protocolo-Setorial-18-

Atividades-Educacionais-1.pdf. Acesso em: 21/12/20.

Saiba como cada estado está retomando as atividades econômicas no país. Agência Brasil, 22 de junho de 2020. Disponível em: https://agenciabrasilebc.com.br/saude/noticia/202006/saiba-como-estados-brasileiros-est $\% \mathrm{C} 3 \% \mathrm{~A} 3 \mathrm{o}$-retomando-a-atividade-economica. Acesso em: 14/12/2020.

SAVIANI, Demerval. História das ideias pedagógicas no Brasil [livro eletrônico]. Campinas, SP: Autores Associados, 2019.

ROCHA, Ubiratan. História, currículo e cotidiano escolar. São Paulo: Cortez, 2002.

Trabalbo oriundo do I Seminário do GPOSSHE - Educação do campo e Pedagogia histórico-crítica em contexto de crise e pandemia. 